\title{
Comparative Study of Intrarenal Vascular Impedance Among Hypertensive Diabetics and Normotensive Type 2 Diabetics In South Western Nigeria
}

\author{
Ademola Joseph Adekanmi ${ }^{1, ~ *, ~ A r i n o l a ~ E s a n ~}{ }^{2}$ \\ ${ }^{1}$ Department of Radiology, College of Medicine, University of Ibadan, Ibadan, Nigeria \\ ${ }^{2}$ Department of Medicine, University College Hospital, Ibadan, Nigeria \\ Email address: \\ kanmiademola@gmail.com(A.J.Adekanmi),a.jadekanmi@ui.edu.ng(A.J. Adekanmi) \\ *Corresponding author
}

\section{To cite this article:}

Ademola Joseph Adekanmi, Arinola Esan. Comparative Study of Intrarenal Vascular Impedance Among Hypertensive Diabetics and Normotensive Type 2 Diabetics In South Western Nigeria. Clinical Medicine Research. Vol. 7, No. 1, 2018, pp. 30-39. doi: $10.11648 /$ j.cmr.20180701.15

Received: February 19, 2018; Accepted: March 13, 2018; Published: April 4, 2018

\begin{abstract}
Diabetes is a serious health problem with staggering morbidity and mortality rates documented to be rising at an alarming rate worldwide, more so in low income countries. The uncontrolled effect of high blood glucose and disease complications have protean multisytemic consequences. Concomitant Diabetes Mellitus (DM) and hypertension accelerates the progression of micro and macro vascular complications including nephropathy. In this prospective comparative study amongst Diabetic hypertensives, normotensive Diabetics and healthy non-diabetic normotensive controls, we evaluated the effect of coexisting hypertension with diabetes and normotensive DM on renal vascular impedance. Demographic, clinico-laboratory data and Duplex ultrasound impedance of the renal interlobar arteries were documented and data analyzed using Statistical Package for Social Sciences (SPSS) version 23 computer software. The Intra-renal Resistive index (RI) among Diabetic hypertensives $($ Mean $=0.72 \pm 0.15)$, normotensive DM patients $($ Mean $=0.69 \pm 0.08)$ and control (Mean $=0.63 \pm 0.08)$ were statistically significant, $F(2,89)=10.94, p<0.001$. The intra renal Doppler RI showed significant correlations with age $(r=0.236$, $\mathrm{p}=0.019)$ and duration of diabetes $(\mathrm{r}=0.333, \mathrm{p}=0.003)$. The Pulsatility index showed statistical significant associations with age $(r=0.370, p<0.001)$, duration of diabetes $(r=0.338, p=0.002)$ and serum creatinine $(r=0.208, p=0.039)$. A unit increase in mean arterial blood pressure increases the risk of concomitant hypertension in DM patients by about $3 \%$ (AOR $=1.03,95 \%$ CI $1.10 ; 1.33, \mathrm{p}<0.001)$. Also, an increase by $1 \mathrm{mg} / \mathrm{dl}$ in cholesterol level increases the risk of concomitant hypertension in DM patients by about $1 \%(\mathrm{AOR}=1.01,95 \%$ CI $1.00 ; 1.02, \mathrm{p}=0.044)$. Altogether concomitant hypertension with DM causes slightly high renal vascular impedance, particularly the RI as well as mild renal dysfunction than in normotensive persons with diabetes. Particularly among cases with clinico-laboratory evidence of good glycaemic control as well as blood pressure management. The arterial blood pressure and cholesterol levels are predictors of concomitant Hypertensive Diabetic status in this study.
\end{abstract}

Keywords: Normotensive, Type 2 Diabetes, Concomitant Hypertension, Resistive Index, Pulsatility Index, Doppler Ultrasonography

\section{Introduction}

Diabetes is a serious threat to population health. The World Health Organization (WHO) estimated the total burden of deaths from high blood glucose in 2012 to sum to about 3.7 million, including 1.5 million diabetes deaths, and an additional 2.2 million deaths from cardiovascular diseases, chronic kidney disease, and tuberculosis related to higherthan-optimal blood glucose [1]. Over the last 3 decades there has been increase in trend in number of people with diabetes. In 2014, globally, 422 million adults aged over 18 years were living with diabetes. According to International Diabetes 
Federation (IDF) [2], this number is estimated to reach 592 million by 2035 with low and middle income countries contributing a substantial proportion. Currently, sub-Saharan Africa is estimated to have 20 million people with diabetes. In sub-Saharan Africa, Nigeria has the highest number of people with diabetes with an estimated 3.9 million people (or an extrapolated prevalence of $4.99 \%$ ) of the adult population aged 20-79-year-old [3]. Studies in Nigeria have reported that the prevalence of diabetes varies across different zones of the country but ranges from $2.2-9.8 \%$ [4-6].

Hypertension (HT) has been identified as the commonest co-morbidity with diabetes mellitus [7] and has been categorized as an asymptomatic chronic condition in diabetes [8]. It is reported to be twice as prevalent in diabetics than in non-diabetic individuals [9] occurring in about $20 \%$ to $75 \%$ of patients with diabetes [10-14]. Hypertension and diabetes are highly related [15] and has been shown to accelerate the progression of both microvascular (retinopathy, nephropathy and neuropathy) and macrovascular (atherosclerotic) complications in diabetic patients [16-19]. Microvascular lesions resulting in glomerulosclerosis and renal arteriosclerosis from macrovascular lesions as well as diabetic nephropathy from infectious, parenchymatous and vascular lesions are documented renal changes in DM [20, 21]. Diabetes has also been reported as the commonest cause of End stage renal disease [21].

Recent studies have demonstrated the effectiveness of blood pressure treatment in reducing the complications of diabetes [22].

Doppler ultrasonography of the renal vasculature has become a reliable, non-invasive ionization radiation-free imaging technique whose clinical application has increased steadily in recent years. Previous studies have demonstrated the usefulness of Doppler ultrasonography in determining abnormalities of renal vasculature in different pathological conditions. Derchi and colleagues [23] reported that a reduction in creatinine clearance and the presence of microalbuminuria are associated with increased renal vascular impedance, as well as with signs of extra renal arterial stiffness among untreated patients with primary hypertension. Also, Bigé et al [24] reported that RI $\geq 0.65$ is associated with severe interstitial fibrosis and arteriosclerosis and renal function decline and concluded that RI could identify patients at high risk of end stage renal diseases who may benefit from nephroprotective treatments.

Other researchers have also documented renal vascular resistance in newly diagnosed Diabetics with or without hypertension [24-28] and untreated primary hypertensives $[23,29]$. However, there is paucity of literature on the concomitant effect of DM and hypertension on renal vascular impedance in currently treated diabetics, particularly in our environment where there is a high prevalence of diabetes and hypertension co-morbidity. This study was to determine the intrarenal vascular impedance in persons with concomitant Diabetes and Hypertension and in normotensive DM patients. We compared these renal impedance with that of healthy normotensive and non-Diabetic controls with normal laboratory parameters as well as determined associations with clinico-laboratory risk factors.

\section{Materials and Methods}

\subsection{Study Design and Population}

This was a prospective comparative study among Adults Diabetic patients with or without hypertension seen and referred to the Endocrinology clinic of a major tertiary health Institution in South Western Nigeria between July 2016 and April 2017. A purposive sampling technique was be used to select consecutive consenting cases and healthy controls. 153 participants were enrolled for this study. Doppler Ultrasonography of the renal interlobar arteries was carried out on all cases and healthy controls.

\subsection{Inclusion Criteria}

Cases were adults aged 18 years and above that met the criteria for Diabetes as defined by WHO [30]. They were further sub-divided into Diabetic hypertensives and normotensive Diabetics by their known blood pressure or on hypertensives drugs. Healthy normotensive, non-diabetic adults without symptoms of Diabetes, renal or vascular diseases or abnormal blood glucose levels were selected as controls.

Those that declined consent, diabetics below age 18 years or existing renal and vascular diseases were excluded from this study.

\subsection{Ethical Consideration}

Ethical approval was obtained from the joint University of Ibadan/University College Hospital ethical review committee. All participants signed an informed consent form. Their participation was voluntary and all participants informed they have the right to withdraw from the study at any time but will still have the required necessary treatment. Confidentiality of participants was preserved by giving numbers instead of real names.

\subsection{Clinical Evaluation}

The clinical parameters of all consenting patients including measurement of blood pressure, weight, and height were recorded and their body mass index calculated. Hypertension was defined by blood pressure measurement equal to or above $140 / 90 \mathrm{mmHg}$ where 140 is the systolic and 90 is diastolic [31]. Their serum creatinine, glycosylated haemoglobin (HbA1c) and lipid profile values and relevant sociodemographic data and clinical risk factors were recorded in the prepared data form.

\subsection{Ultrasonographic Examination}

All participants were evaluated using a General electric Logic P5 ultrasound scanner with Doppler capability and a trans-abdominal pulsed, 2 to $5 \mathrm{MHz}$ curvilinear transducer. To avoid inter-observer variability all Doppler examinations were 
done by the same qualified Radiologist with vast experience in vascular studies. All subjects were scanned in the supine position after an overnight fast and during suspended respiration at inspiration. The kidneys were scanned on Bmode Ultrasound to locate the kidneys and colour Doppler to visualize the interlobar arteries. Afterwards Doppler interrogation of the interlobar arteries was carried out. The wall filter was set to $50 \mathrm{~Hz}$ and the sample volume was set at 2-5 $\mathrm{mm}$ and adjusted as appropriate. The RI and PI were measured after 3 consecutive waveform cycles. The mean of the RI and PI were recorded and documented in the data form.

\subsection{Data Analysis}

The data was entered and analyzed using the statistical package for social sciences (SPSS) version 23.0 (SPSS,
Chicago, IL, USA). Test of association between qualitative variables using Chi square test while the student t-test was used to test association between quantitative variables at $5 \%$ level of significance. The correlation between two variables was assessed by the Spearman coefficient. Categorical data were expressed as percentages. The $\chi^{2}$ or Fisher exact test was applied as appropriate.

\section{Results}

\subsection{Clinico-Demographic Characteristics of the Study Population}

The Demographic and clinical characteristics of the studied population are reported in Table 1 .

Table 1. Age and sex distribution among the study population.

\begin{tabular}{|c|c|c|c|c|}
\hline \multirow{2}{*}{ Subject variables } & \multicolumn{4}{|c|}{ Type 2 DM with hypertension } \\
\hline & Present & Absent & Control & P-value \\
\hline \multicolumn{5}{|l|}{ Age in group } \\
\hline Below 40 years & $2(4.3)$ & $2(3.8)$ & $2(3.8)$ & \multirow{5}{*}{0.999} \\
\hline 41 to 50 years & $7(14.9)$ & $10(18.9)$ & $11(20.8)$ & \\
\hline 51 to 60 years & $13(27.7)$ & $14(26.4)$ & $15(28.3)$ & \\
\hline 61 to 70 years & $20(42.6)$ & $22(41.5)$ & 21 (39.6) & \\
\hline Above 70 years & $5(10.6)$ & $5(9.4)$ & $4(7.5)$ & \\
\hline \multicolumn{5}{|l|}{ Sex } \\
\hline Male & $16(28.3)$ & $15(34)$ & $20(37.7)$ & \multirow[t]{2}{*}{0.604} \\
\hline Female & 31 (71.7) & $38(66)$ & $33(62.3)$ & \\
\hline
\end{tabular}

Expectedly, the mean Systolic blood pressure of hypertensive DM $($ HTDM) patients $($ Mean $=139.1 \pm 21.70$ $\mathrm{mmHg}$ ) is significantly higher than the mean Systolic blood pressure of normotensive DM patients (Mean $=118.5 \pm 9.46$ $\mathrm{mmHg}$ ) and the mean Systolic blood pressure of the controls $($ Mean $=109.0 \pm 8.11 \mathrm{mmHg})$ respectively $[\mathrm{F}(2,89)=$ $46.38, \mathrm{p}<0.001]$. Also, the mean Systolic blood pressure of normotensive DM patients was significantly higher than the mean systolic pressure of the controls. The differences in mean between the Diastolic blood pressure $[\mathrm{F}(2,86)=$ $14.01, \mathrm{p}<0.001]$ and the Mean arterial pressure (MAP) [F (2, $88)=29.37, \mathrm{p}<0.001]$ among the groups also followed the same pattern. However, the mean Diastolic B. P and MAP for normotensive DM patients and control cases did not differ significantly.

Although the mean serum creatinine level of Hypertensive DM patients was not statistically significantly different from the mean serum creatinine level of normotensive DM patients the mean serum creatinine level of the controls (Mean = $0.56 \pm 0.26$ ) was statistically significantly lower than the mean serum creatinine level of Hypertensive DM patients (Mean = $1.41 \pm 0.74)$ and normotensive DM patients (Mean $=1.24 \pm$ $0.56)$ respectively $[\mathrm{F}(2,88)=52.74, \mathrm{p}<0.001$. Likewise, the result also showed a significant higher mean waist circumference among hypertensive DM patients $(\mathrm{M}=92.92$ $\pm 12.93 \mathrm{~cm}$ ) and normotensive DM patients (Mean $=92.29 \pm$ $11.16 \mathrm{~cm})$ compared to the mean waist circumference of controls $($ Mean $=80.36 \pm 8.20 \mathrm{~cm})[\mathrm{F}(2,94)=27.46, \mathrm{p}<$ 0.001]. Also, the mean HbA1c level in hypertensive DM $(\mathrm{HTDM})$ patients $($ Mean $=5.88 \pm 0.93)$ and the mean HbA1c level of normotensive DM (NDM) patients (Mean $=5.59 \pm$ 0.75 ) each were statistically significantly higher than the mean $\mathrm{HbA1c}$ level of the controls (Mean $=4.99 \pm 0.36$ ) respectively $[\mathrm{F}(2,77)=20.95, \mathrm{p}<0.001]$, this is expected because the control subjects don't have diabetes. There was no statistical significant difference between the means of HbAc1 level in HTDM and NDM patients. Similarly, the mean FBS in HTDM $($ Mean $=122.5 \pm 21.99)$ and that of NDM patients (Mean $=124.7 \pm 28.68)$ each were statistically significantly higher than the mean FBS level of the controls $(\mathrm{n}=53$, Mean $=80.85 \pm 15.26)$ respectively $[\mathrm{F}(2,150)=$ $61.90, \mathrm{p}<0.001]$. However, there was no statistical significant difference between the means of FBS level in Diabetic hypertensives and DM patients without Hypertension (Table 2). 
Table 2. Clinico-laboratory parameters of the study population.

\begin{tabular}{|c|c|c|c|c|c|c|c|c|}
\hline \multirow{3}{*}{ Variables } & \multicolumn{3}{|c|}{ Diabetics with hypertension } & \multicolumn{5}{|c|}{ Post hoc test } \\
\hline & $\begin{array}{l}\text { Present } \\
\text { (GRP 1) }\end{array}$ & $\begin{array}{l}\text { Absent } \\
\text { (GRP 2) } \\
\end{array}$ & $\begin{array}{l}\text { Control } \\
\text { (GRP 3) } \\
\end{array}$ & \multirow[t]{2}{*}{$\mathbf{F}$} & \multirow[t]{2}{*}{ P-value } & \multirow[t]{2}{*}{ Result } & \multirow{2}{*}{$\begin{array}{l}\text { Mean } \\
\text { dif }\end{array}$} & \multirow{2}{*}{$\begin{array}{l}\text { (95\% CI Mean } \\
\text { dif.) }\end{array}$} \\
\hline & $\bar{X} \pm S D$ & $\bar{X} \pm S D$ & $\bar{X} \pm S D$ & & & & & \\
\hline \multirow[t]{2}{*}{ Weight (kg) } & $63.57 \pm 6.85$ & $65.63 \pm 14.47$ & $64.51 \pm 7.62$ & 0.500 & 0.608 & & & \\
\hline & & & & & & $1>2$ & 20.59 & $(12.37,28.81)$ \\
\hline \multirow[t]{2}{*}{ Systolic B. P(mmHg) } & $139.1 \pm 21.70$ & $118.5 \pm 9.46$ & $109.0 \pm 8.11$ & $46.380 *$ & $<0.001$ & $1>3$ & 30.03 & $(21.95,38.10)$ \\
\hline & & & & & & $2>3$ & 9.43 & $(5.36,13.51)$ \\
\hline \multirow{2}{*}{ Diastolic B.P (mmHg) } & $83.43 \pm 14.05$ & $72.42 \pm 8.41$ & & & & $1>2$ & 11.01 & $(6.38,15.64)$ \\
\hline & $83.43 \pm 14.05$ & $12.42 \pm 8.41$ & $11.92 \pm 5.39$ & $14.00 / \%$ & $<0.001$ & $1>3$ & 11.50 & $(6.87,16.13)$ \\
\hline \multirow{5}{*}{$\begin{array}{l}\text { Mean arterial blood } \\
\text { pressure } \\
\text { Serum } \\
\text { creatinine }(\mathrm{mg} / \mathrm{dl}) \\
\text { BMI }\end{array}$} & $1020+1530$ & $8777+715$ & $8430+521$ & 29367 & $<0001$ & $1>2$ & 14.20 & $(9.49,18.92)$ \\
\hline & $102.0 \pm 10.00$ & & & 29.501 & $<0.001$ & $1>3$ & 17.68 & $(12.96,22.39)$ \\
\hline & $1.41+0.74$ & $124+0.56$ & $0.56+0.26$ & $52742 *$ & $<0001$ & $1>32>3$ & 0.85 & $(0.58,1.13)$ \\
\hline & & & & 32.142 & & $1>5<>3$ & 0.67 & $(0.47,0.88)$ \\
\hline & $24.72 \pm 2.78$ & $25.32 \pm 4.91$ & $25.22 \pm 3.97$ & 0.314 & 0.731 & & & \\
\hline HbA1c (\%) & $5.88 \pm 0.93$ & $5.59 \pm 0.75$ & $4.99 \pm 0.36$ & $20.949 *$ & $<0.001$ & $1>32>3$ & 0.89 & $(0.51,1.26)$ \\
\hline $\begin{array}{l}\text { Cholesterol level } \\
(\mathrm{mg} / \mathrm{dl})\end{array}$ & $169.5 \pm 57.18$ & $157.9 \pm 42.41$ & & 1.340 & 0.250 & & & \\
\hline waist circumference & $92.92 \pm 12.93$ & $92.29 \pm 11.16$ & $80.36 \pm 8.20$ & $27.464 *$ & $<0.001$ & $1>32>3$ & $\begin{array}{l}12.56 \\
11.93\end{array}$ & $\begin{array}{l}(7.31,17.81) \\
(740.16 .46)\end{array}$ \\
\hline Duration of diabetes & $11.37 \pm 9.57$ & $7.89 \pm 5.67$ & & $3.640 *$ & 0.062 & & & \\
\hline $\mathrm{HDL}(\mathrm{mg} / \mathrm{dl})$ & $41.44 \pm 14.52$ & $43.97 \pm 31.06$ & & 0.257 & 0.613 & & & \\
\hline LDL(mg/dl) & $125.3 \pm 82.54$ & $123.6 \pm 75.06$ & & 0.012 & 0.914 & & & \\
\hline TGL(mg/dl) & $121.2 \pm 47.38$ & $116.1 \pm 55.56$ & & 0.240 & 0.625 & & & \\
\hline FBS(mg/dl) & $122.5 \pm 21.99$ & $124.7 \pm 28.68$ & $80.85 \pm 15.26$ & 61.897 & $<0.001$ & $1>32>3$ & $\begin{array}{l}41.62 \\
43.89\end{array}$ & $(30.86,52.37)$ \\
\hline PPBS(mg/dl) & $135.3 \pm 43.32$ & $122.1 \pm 17.79$ & & $3.765 *$ & 0.057 & & & \\
\hline $\begin{array}{l}\text { Urinary } \\
\text { albumin(mg/dl) }\end{array}$ & $108.2 \pm 42.77$ & $105.6 \pm 45.39$ & & 0.084 & 0.773 & & & \\
\hline
\end{tabular}

*Asymptotically F distributed. Welch test.

\subsection{Antihypertensive Medications}

Out of 41 patients whose drug history was documented apart from the hypoglycaemic agents, about $41.9 \%$ of the patients were on combinations of anti-hypertensive drugs. Majority of patients were on (32.6\%) Nifedipine followed by Amlodipine (22.4\%). $12.5 \%$ use Lisinopril, while Aldomet and Hydrochlorothiazide showed an equal usage of $10.0 \%$ each. Moduretic were the medications used in $7.5 \%$. The least used drugs in terms of frequency were Telmisartan (2.5\%) and Ramipril (2.5\%).

\subsection{Intrarenal Doppler Evaluation Among the Study Population}

The difference in mean of the Intra-renal Doppler parameter $(\mathrm{RI})$ among HTDM (Mean $=0.72 \pm 0.15)$, NDM patients (Mean $=0.69 \pm 0.08)$ and control (Mean $=0.63 \pm$ $0.08)$ were statistically significant, $F(2,89)=10.94, p$ $<0.001$. Post hoc tests showed that the mean RI of both HTDM and NDM patients were statistically significantly higher than in control cases. Pairwise comparison among Diabetics however showed that, the mean RI for HTDM and NDM patients did not differ significantly.

There was no statistical difference in the mean intra-renal PI among HTDM, NDM patients and the controls in this study (Table 3).

Among the Diabetics, the trend of the intrarenal RI and PI is shown in table 4 . There is a consistent statistically significant increase in the mean values of the RI ad PI as the age of the subjects and the duration of DM increases (Table 4).

Table 3. Renal intrarenal Resistive and Pulsatility index in the study population.

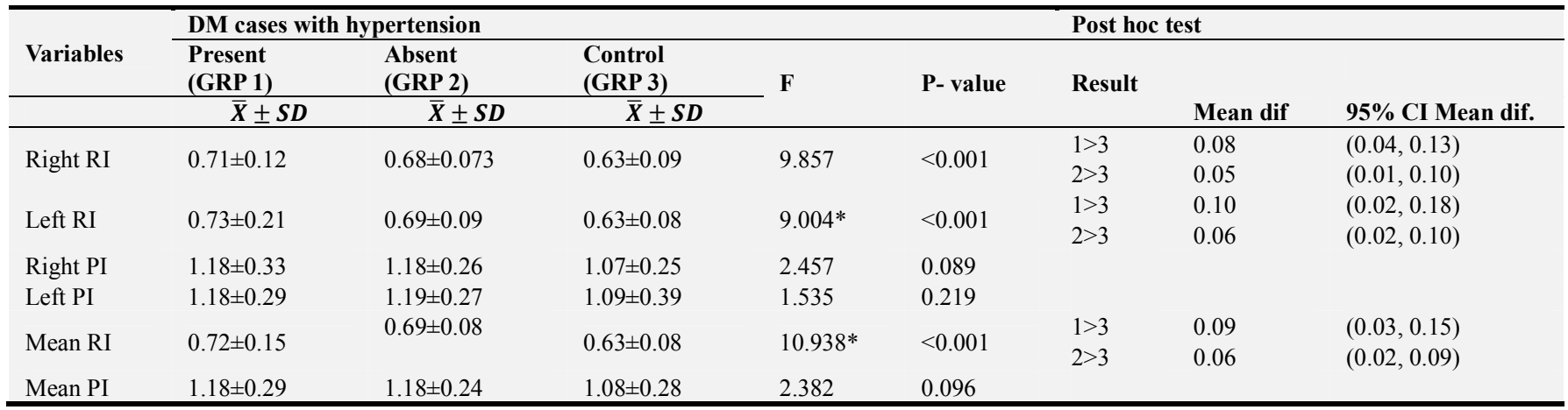

*Asymptotically F distributed. Welch test. $\mathrm{RI}=$ resistive index; $\mathrm{PI}=\mathrm{Pul}$ satility index; $\mathrm{SD}=$ standard deviation; $\mathrm{CI}=$ confidence interval. $\mathrm{P} \leq 0.05$ is significant 
Table 4. Pattern of RI and PI in relation to age and duration of Diabetes among the cases.

\begin{tabular}{|c|c|c|c|c|}
\hline \multirow{2}{*}{ Parameters } & \multicolumn{2}{|l|}{ RI } & \multicolumn{2}{|l|}{ PI } \\
\hline & $\bar{X} \pm S D$ & $\mathbf{P *}$ & $\bar{X} \pm S D$ & $\mathbf{P *}$ \\
\hline \multicolumn{5}{|l|}{ Age in group } \\
\hline 40 years and below & $0.59 \pm 0.05$ & \multirow{6}{*}{0.015} & $1.00 \pm 0.13$ & \multirow{7}{*}{0.027} \\
\hline 41 to 50 years & $0.69 \pm 0.11$ & & $1.06 \pm 0.21$ & \\
\hline 51 to 60 years & $0.70 \pm 0.08$ & & $1.13 \pm 0.19$ & \\
\hline 61 to 70 years & $0.71 \pm 0.11$ & & $1.21 \pm 0.26$ & \\
\hline Above 70 years & $0.74 \pm 0.21$ & & $1.43 \pm 0.36$ & \\
\hline \multicolumn{3}{|l|}{ DM Duration } & & \\
\hline 5 years and below & $0.68 \pm 0.09$ & & $1.11 \pm 0.21$ & \\
\hline 6 to 10 years & $0.71 \pm 0.10$ & & $1.19 \pm 0.20$ & \multirow{3}{*}{0.003} \\
\hline 11 to 15 years & $0.75 \pm 0.05$ & 0.002 & $1.26 \pm 0.24$ & \\
\hline Above 15 years & $0.78 \pm 0.23$ & & $1.43 \pm 0.43$ & \\
\hline
\end{tabular}

*Asymptotically $\mathrm{F}$ distributed. (Welch test). $\mathrm{DM}=$ diabetes mellitus; $X=$ mean; $S D=$ standard deviation; $P * \leq .05$ is sttatistically signif cant.

\subsubsection{Resistive Index Classification of the Diabetic Groups and Comparison with Serum Creatinine and eGFR}

The diabetic hypertensives and normotensive diabetes were divided into low and high RI $(<0.65$ or $\geq 0.65$ respectively) subgroups in accordance with the work of Bigé and colleagues [24]. Among DM patients, those with concomitant hypertension had higher mean serum creatinine values $(\mathrm{M}=1.28 \pm 0.68$ and $\mathrm{M}=1.45 \pm 0.79)$ among the low and high RI subgroups respectively than in NDM patients (Figure 1).

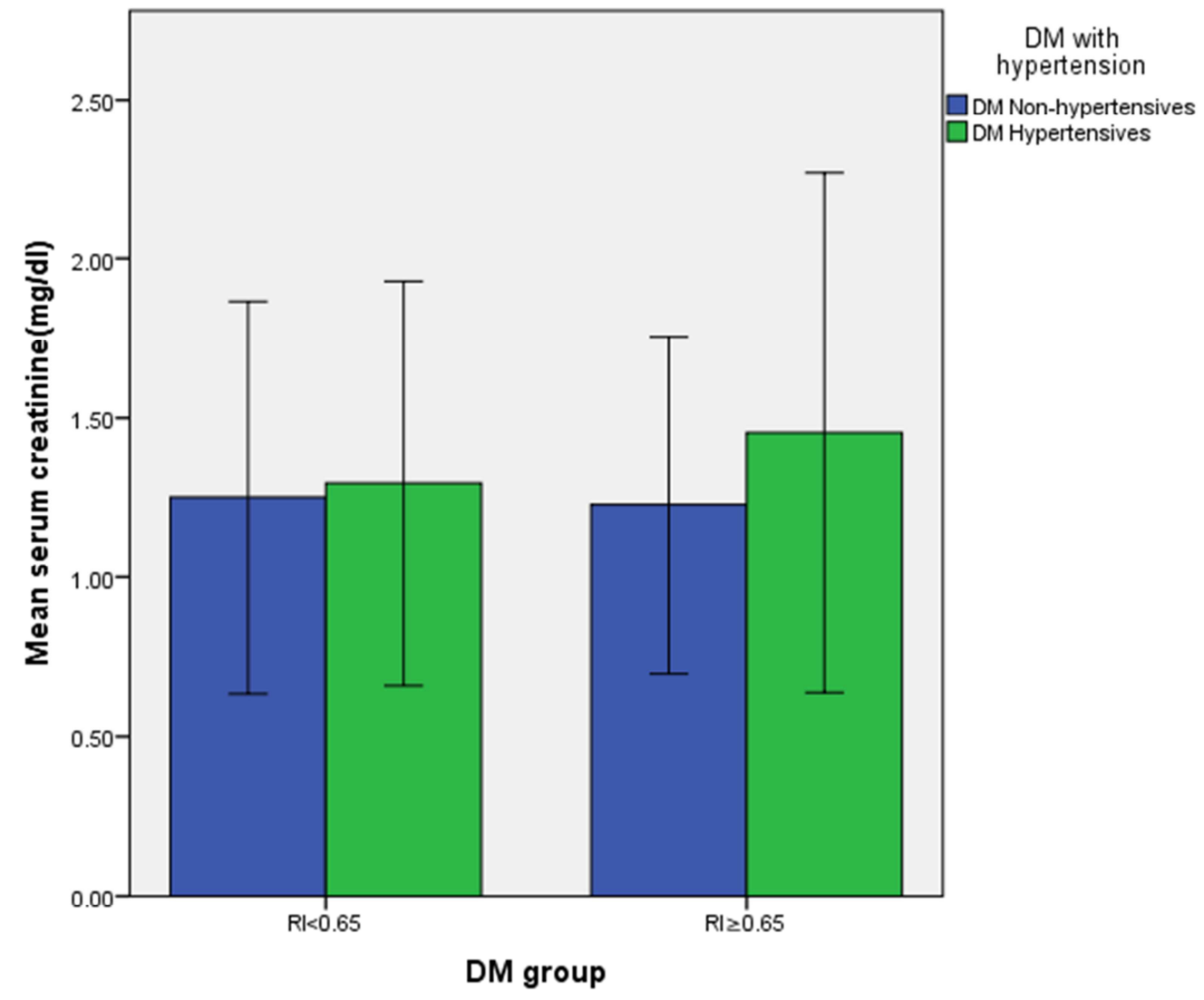

The error bar shows the standard deviation.

Figure 1. Bar chart showing the serum creatinine levels in the Diabetic subgroups.

Furthermore among DM patients with $\mathrm{RI}<0.65$ and those with $\mathrm{RI} \geq 0.65$, DM patients with concomitant hypertension and DM had lower mean eGFR values in both groups $(\mathrm{M}=74.72 \pm 40.56$ and $\mathrm{M}=61.18 \pm 36.42)$ respectively than in NDM patients (Figure 2). 


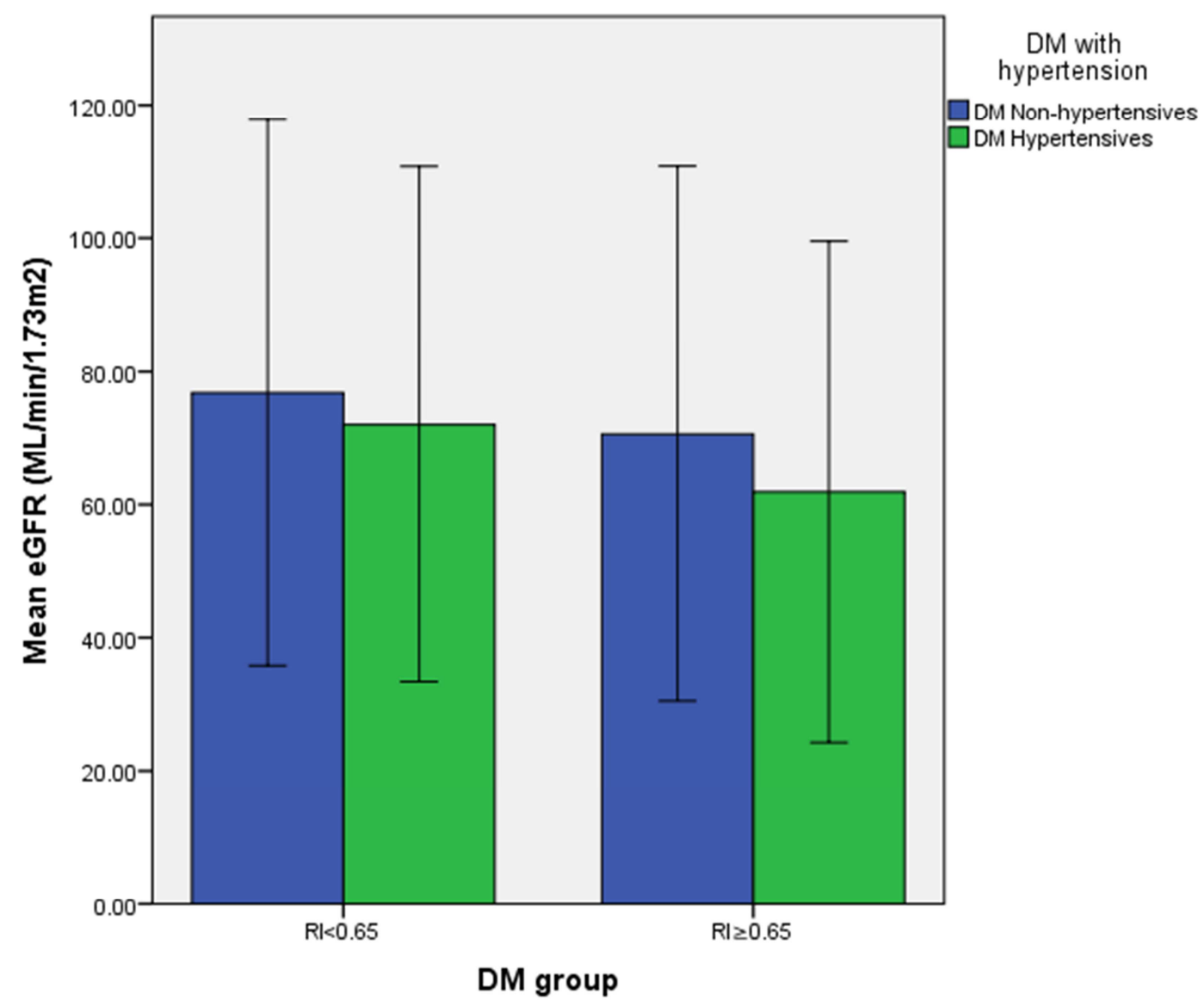

The error bar depicts the standard deviation.

Figure 2. Bar chart of the diabetic group according to the eGFR and RI.

\subsubsection{Correlation between Intrarenal Impedance and Clinical risk Factor Among the Diabetics}

The intra renal Doppler RI showed statistical significant correlations with age $(\mathrm{r}=0.236, \mathrm{p}=0.019)$ and duration of diabetes $(\mathrm{r}=0.333, \mathrm{p}=0.003)$. While the intra renal Doppler PI also showed statistical significant associations with age $(r=0.370$, $p<0.001)$, duration of diabetes $(r=0.338, p=0.002)$ and serum creatinine level $(r=0.208, p=0.039)$ as shown in Table 5 .

Table 5. Correlation between renal RI and PI with clinical risk factors among Diabetics.

\begin{tabular}{|c|c|c|c|c|c|c|}
\hline \multirow{2}{*}{ Clinical risk factors } & \multicolumn{3}{|l|}{ Resistive Index } & \multicolumn{3}{|l|}{ Pulsatility index } \\
\hline & Correlation coefficient & p-value & $\mathbf{N}$ & Correlation coefficient & p-value & $\mathbf{N}$ \\
\hline Age & 0.236 & 0.019 & 98 & 0.370 & $<0.001$ & 98 \\
\hline waist circumference & -0.001 & 0.995 & 98 & 0.046 & 0.650 & 98 \\
\hline Duration of diabetes & 0.333 & 0.003 & 78 & 0.338 & 0.002 & 78 \\
\hline cholesterol level (mg/dl) & -0.001 & 0.992 & 98 & -0.194 & 0.056 & 98 \\
\hline HbA1c (\%) & -0.034 & 0.742 & 98 & 0.053 & 0.604 & 98 \\
\hline BMI & 0.136 & 0.183 & 98 & -0.035 & 0.735 & 98 \\
\hline Systolic blood pressure & 0.185 & 0.069 & 98 & -0.001 & 0.989 & 98 \\
\hline Diastolic blood pressure & 0.122 & 0.230 & 98 & -0.017 & 0.868 & 98 \\
\hline Mean arterial blood pressure & 0.169 & 0.096 & 98 & -0.034 & 0.738 & 98 \\
\hline Serum creatinine & 0.064 & 0.532 & 98 & 0.208 & 0.039 & 98 \\
\hline
\end{tabular}

$P$ value $\leq 0.05$ is statistically significant.

\subsubsection{Factors Associated with Concomitant Hypertension and DM in the Study Population}

There was a statistical significant difference in the SBP, DBP and mean arterial blood pressure between NDM patients $(\mathrm{M}=139.1 \pm 21.70,118.5 \pm 9.6$ and $87.77 \pm$
$7.15 \mathrm{mmHg})$ and HTDMs $(\mathrm{M}=83.43 \pm 14.05 ; 72.42 \pm 8.41$ and $102.0 \pm 15.30 \mathrm{mmHg})(\mathrm{p}<0.001)$. The patient's age, cholesterol level, serum creatinine, Urinary albumin and duration of diabetes however showed no such association (Table 6). 
Table 6. Association between Concomitant Hypertensive Diabetic state, selected clinico-laboratory risk factors and renal vascular impedance.

\begin{tabular}{|c|c|c|c|c|c|c|c|c|c|c|}
\hline & \multicolumn{5}{|c|}{ DIABETIC GROUPS } & \multirow{2}{*}{\multicolumn{2}{|c|}{$\begin{array}{l}\text { 95\% CI for Mean } \\
\text { Difference }\end{array}$}} & \multirow[b]{3}{*}{$\mathbf{t}$} & \multirow[b]{3}{*}{ df } & \multirow[b]{3}{*}{ p-value } \\
\hline & \multicolumn{3}{|c|}{ Hypertensive DM } & \multicolumn{2}{|c|}{ Normotensive DM } & & & & & \\
\hline & Mean & SD & $\mathbf{n}$ & Mean & SD & $\mathbf{n}$ & & & & \\
\hline Age & 60.55 & 10.67 & 47 & 59.30 & 10.00 & 53 & $5.35,-2.85$ & 0.605 & 98 & 0.547 \\
\hline waist circumference & 92.92 & 12.93 & 47 & 92.29 & 11.16 & 53 & $5.41,-4.15$ & 0.263 & 98 & 0.793 \\
\hline BMI & 24.72 & 2.78 & 47 & 25.32 & 4.91 & 53 & $0.96,-2.17$ & -0.763 & 84 & 0.448 \\
\hline Duration of diabetes (years) & 11.37 & 9.57 & 35 & 7.89 & 5.67 & 45 & $7.15,-0.18$ & 1.908 & 52 & 0.062 \\
\hline Cholesterol level (mg/dl) & 169.5 & 57.18 & 47 & 157.9 & 42.41 & 53 & $31.40,-8.27$ & 1.157 & 98 & 0.250 \\
\hline HbAlc $(\%)$ & 5.88 & 0.93 & 47 & 5.59 & 0.75 & 53 & $0.62,-0.049$ & 1.694 & 98 & 0.093 \\
\hline Serum creatinine & 1.41 & 0.74 & 47 & 1.24 & 0.56 & 53 & $0.44,-0.08$ & 1.375 & 98 & 0.172 \\
\hline Urinary albumin (mg/dl) & 108.2 & 42.77 & 46 & 105.6 & 45.39 & 50 & $20.53,-15.30$ & 0.290 & 94 & 0.773 \\
\hline Systolic blood pressure $(\mathrm{mmHg})$ & 139.1 & 21.70 & 47 & 118.5 & 9.46 & 53 & $13.75,27.43$ & 6.017 & 61 & $<0.001$ \\
\hline Diastolic blood pressure $(\mathrm{mmHg})$ & 83.43 & 14.05 & 47 & 72.42 & 8.41 & 53 & $6.32,15.70$ & 4.680 & 73 & $<0.001$ \\
\hline $\mathrm{eGFR}\left(\mathrm{mL} / \mathrm{min} / 1.73 \mathrm{~m}^{2}\right)$ & 64.76 & 37.50 & 45 & 72.96 & 40.23 & 53 & $-23.80,7.39$ & -1.044 & 97 & 0.299 \\
\hline Mean arterial blood pressure & 102.0 & 15.30 & 47 & 87.77 & 7.15 & 53 & $9.33,19.07$ & 5.824 & 63 & $<0.001$ \\
\hline Kidney RI & 0.72 & 0.15 & 45 & 0.69 & 0.08 & 53 & $0.08,-0.02$ & 1.387 & 64 & 0.170 \\
\hline Kidney PI & 1.18 & 0.29 & 45 & 1.18 & 0.24 & 53 & $0.10,-0.11$ & -0.052 & 96 & 0.959 \\
\hline
\end{tabular}

$\mathrm{BMI}=$ body mass index; $\mathrm{RI}=$ resistivity index; $\mathrm{PI}=$ Pulsatility index; $\mathrm{SD}=$ standard deviation; $\mathrm{t}=$ students' test; $\mathrm{n}=$ number of cases; $\mathrm{CI}=\mathrm{confidence}$ interval; eGFR $=$ estimated glomerular filtration rate and $\mathrm{P} \leq 0.05$ is statistically significant.

Also in this study, there was no statistical significant association between sex and hypertension in DM patients; $\mathrm{X}^{2}$ $=0.384$ and $\mathrm{P}=0.536$.

\subsubsection{Predictors of Diabetic Hypertensive Co-Morbidity in the Study Population}

After adjusting for confounders, among all factors considered, the Mean arterial blood pressure was statistically significant associated with hypertension in DM. A unit increase in mean arterial blood pressure increases the risk of hypertension in $\mathrm{DM}$ patients by about 3\% $(\mathrm{AOR}=1.03,95 \%$ CI $1.10 ; 1.33, \mathrm{p}<0.001)$. Also, an increase by $1 \mathrm{mg} / \mathrm{dl}$ in cholesterol level increases the risk of hypertension in DM patients by about $1 \%(\mathrm{AOR}=1.01,95 \%$ CI $1.00 ; 1.02, \mathrm{p}=$ 0.044). However, hypertension in DM was not statistically significantly associated with the intra renal RI and PI as shown in table 7.

Table 7. Multivariate analysis of hypertension in DM patients and predictors.

\begin{tabular}{|c|c|c|c|c|}
\hline \multirow{2}{*}{ Variables } & \multirow{2}{*}{ Adjusted OR } & \multicolumn{2}{|c|}{ 95\% confidence Interval } & \multirow{2}{*}{ P-Value } \\
\hline & & Lower & Upper & \\
\hline Mean RI & 0.74 & 0.002 & 254.5 & 0.920 \\
\hline Mean PI & 0.26 & 0.01 & 6.20 & 0.406 \\
\hline cholesterol level (mg/dl) & 1.01 & 1.00 & 1.02 & 0.044 \\
\hline VLDL(mg/dl)-HBA $\mathrm{H}_{1} \mathrm{C}$ & 1.76 & 0.76 & 4.06 & 0.185 \\
\hline BMI & 1.06 & 0.91 & 1.25 & 0.454 \\
\hline Mean arterial blood pressure & 1.21 & 1.10 & 1.33 & $<0.001$ \\
\hline Serum creatinine & 0.63 & 0.19 & 2.11 & 0.455 \\
\hline Duration of diabetes & 1.07 & 0.94 & 1.22 & 0.292 \\
\hline \multicolumn{5}{|l|}{ Sex } \\
\hline Male & 1 & & & \\
\hline Female & 1.720 & 0.35 & 8.58 & 0.842 \\
\hline
\end{tabular}

\section{Discussion}

Diabetes and hypertension are major causes of microvascular and macrovascular complications with attendant high morbidity and mortality. Concomitant hypertension, which occurs in $20-75 \%$ of DM cases further accelerates and worsens already serious cardiovascular complications. In this study, age group and gender matched participants were enrolled. There were no statistical differences in the ages and sex of the 3 groups, this may reduce the effect of age and gender as confounders in this study. The observed statistically higher systolic, diastolic and mean arterial blood pressure, is expected due to the concomitant hypertension in the Diabetic group. Diabetes and/or hypertension could cause deranged renal function with consequent high serum creatinine levels as demonstrated in this study. HbA1c levels though higher in the Diabetic groups was within the normal limits of normal values. This showed good compliance with medications and other management protocols with good glycaemic control of the chronic exposure to glucose among diabetics in this study [32-33]. The waist circumference (WC), a reflection of subjects' abdominal adiposity was higher in the Diabetics, similar to the higher BMI observed in diabetic groups compared to the controls. High WC and BMI, both indicators of obesity, have been documented to be positively associated with DM [34-36].

The mean values of the WC and BMI of Diabetics in this study, though slightly higher in the Diabetic hypertensives showed that most Diabetic patient are overweight, despite 
being on treatment for years.

In the study population, the presence of diabetes mellitus significantly affects the intra renal RI with higher values in persons with diabetes, this is in agreement with the work of Ishimura and co-workers [37] that reported that intra renal RI can be a marker of systemic arteriosclerosis caused by modifiable factors like HT, dyslipidaemia, DM, aging and smoking. Mean RI of 0.72 and 0.61 were observed amongst Diabetics and control in this study in agreement with previous research work [38]. However, no such changes was observed with the PI. Although some researchers documented significant differences in PI between persons with Diabetes and normal control subjects [38, 39]. We postulate that amongst DM cases, good compliance to treatment possibly reverts the PI to almost normal values before the RI changes, thus accounting for the lack of difference of PI values between the groups. According to literature reports, the RI and PI show consistent increase as the age of the subjects increases both in persons with diabetes and in normal healthy controls. The reasons postulated for this were increasing arteriosclerotic change with age and resultant intrarenal vascular resistance [37, 40-41]. Our findings among persons with DM also corroborates this.

Similarly we observed increasing RI and PI with increasing duration of DM; this is probably due to worsening effect of atherosclerosis as duration of DM increases with consequent high vascular resistance.

Expectedly, concomitant HT with DM has been reported to significantly increase the intrarenal RI and PI than in normotensive persons with diabetes due to the confounding effect of hypertension on DM causing worsening atherosclerosis and vessel wall stiffening with resultant increase in the renal vascular resistance $[38,42]$. Our study however differs on this, as the RI though slightly higher in HTDM than in normotensive Diabetics was not significantly different. Reasons for this difference may be due to differences in study design and methodology. In these works, the researchers did not specify whether their cases were newly diagnosed, untreated or the antihypertensive drugs were discontinued before Doppler interrogation of the renal vessels. In this study patients had their medications during the course of this research. Furthermore we observed that the intra-renal PI showed no differences among the Diabetics and healthy control and between HTDM and normotensive DM patients in agreement with previous study by Panaritis and colleagues [43].

Although the added athereoscreotic effect of hypertension should have caused a significant change in the renal impedance, we believed that the pharmacological effect of the anti-hypertensives drugs (Angiotensin converting enzyme inhibitors and Angiotensin receptor antagonists [44], calcium channel blockers $[45,46]$ and beta blockers) on renal vessel vasodilation and subsequent reduction of vascular resistance over time is most probably the major factor for the lack of much disparity in the renal impedance parameters among these 2 groups. Good glycaemic control also would have slowed down the expected high renal vascular resistance from microvascular effect of DM.

Although, Lorenzo and colleagues also observed a slight increase in renal vascular impedance at the interlobar arteries, in patients with primary hypertension. They however reported an association between the observed slight renal vascular impedance increase and subclinical abnormalities of renal function. This is similar to the observed slightly high RI in hypertensive Diabetics in this study.

Reports from Bigé and colleagues [24] suggested that RI $\geq$ 0.65 is associated with severe interstitial fibrosis and arteriosclerosis and consequently declining renal function. They concluded that RI may be important in identifying patients at high risk of end stage renal diseases. Using this RI cut off, we observed that the serum creatinine levels were higher in subjects with HTDM and their eGFR lower than in normotensive persons with diabetes thus stressing the fact that concomitant Diabetes Mellitus and hypertension has some summation effect on the renal function, even when well managed with medications.

Furthermore the observed lack of intra-renal PI differences among the normotensive Diabetics and hypertensive Diabetic is in agreement with the work of Paneritis and colleagues previous study [43]. We postulate that the anti-hypertensive drugs lowers the intrarenal PI at a faster rate than the RI during treatment. More population based studies are necessary to address the pharmacological effect of antihypertensive drugs on renal vessel vasodilation and vascular resistance parameters.

Correlations of RI and PI with selected risk factors showed that the RI increases with increasing patient's age and duration of diabetes. This observation may be due to the increasing effect of atherosclerosis as these risk factors have been associated with atherosclerosis [38]. Increase in serum creatinine level also showed correlations with increasing PI but not RI. It is possible the PI is more sensitive to changes in renal function than RI. This could not be corroborated as there is dearth of literature on the serum creatinine and PI indices in patients with concomitant hypertension and Diabetes.

In this study, predictors of HTDM status were the mean arterial blood pressure and cholesterol levels. A unit increase in mean arterial blood pressure increases the risk of hypertension in $\mathrm{DM}$ patients by about $3 \%(\mathrm{AOR}=1.03,95 \%$ CI $1.10 ; 1.33, \mathrm{p}<0.001)$. Also, an increase by $1 \mathrm{mg} / \mathrm{dl}$ in cholesterol level increases the risk of hypertension in DM patients by about $1 \%(\mathrm{AOR}=1.01,95 \%$ CI $1.00 ; 1.02, \mathrm{p}=$ 0.044). The RI and PI were not predictors of HTDM in long standing DM with good blood pressure and glycaemic control probably due to the vasodilation effect of the antihypertensive medications.

Monitoring of the renal impedance may become an important tool to evaluate response to therapeutic effect of antihypertensive drugs among Diabetic hypertensives in the future.

Limitation in this study is that newly diagnosed Diabetic hypertensives were not included in the study design. Future studies would explore the effect of renal impedance in this particular group of patients. 


\section{Conclusion}

This study has shown that even with good blood pressure management and glycaemic control, concomitant hypertension with DM causes slightly high renal vascular impedance, particularly the RI as well as mild renal dysfunction than in normotensive persons with diabetes.

The RI is a more constant Doppler parameter than PI in renal vascular resistance evaluation, even among healthy people.

While the blood pressure is positively associated HTDM, the arterial blood pressure and cholesterol are predictors of concomitant Diabetic-Hypertensive status in this study.

\section{Acknowledgements}

We thank the staff and resident doctors of the Endocrine unit of Department of Medicine and the Ultrasound suite of department of Radiology, UCH Ibadan for their assistance and cooperation. We also thank Mr. Alex Omowumi for the data analysis of this work

\section{Conflict of Interest}

The authors declare that they have no competing interests.

\section{Authors' Contribution}

$\mathrm{AAJ}$ and $\mathrm{AE}$ designed the research. AAJ performed the ultrasound scanning. AAJ wrote the manuscript. AE proof read the manuscript. Both authors read and approved the final manuscript.

\section{References}

[1] WHO Mortality Database [online database]. Geneva: World Health Organization;

(http://apps.who.int/healthinfo/statistics/mortality/causeofdeat h_query/).

[2] IDF Diabetes Atlas, 6th ed. Brussels, International Diabetes Federation; 2013.

[3] World Health Assembly. Follow-up to the Political Declaration of the High-level Meeting of the General Assembly on the Prevention and Control of Noncommunicable Diseases. Geneva: World Health Organization; 2013.

[4] Akinkugbe OO (Editor). Non communicable diseases in Nigeria: national survey (final report) on hypertension, coronary heart disease, diabetes mellitus, G6PD deficiency and anaemia. National Expert Committee on NonCommunicable Disease. Federal Ministry of Health and Social Services, Lagos, 1997.

[5] Chinenye S, Ogbera AO. Socio-cultural aspects of diabetes mellitus in Nigeria. J Soc Health Diabetes. 2013; 1(1): 15-21.

[6] Nyenwe EA, Odia OJ, Ihekwaba AE, Ojule A, Babatunde S. Type 2 diabetes in adult Nigerians: a study of its prevalence in Port Harcourt, Nigeria. Diabetes Res Clin Pract. 2003; 62:

\section{$177-185$.}

[7] Okafor, C., Fasanmade, O. A. and Oke, D. A. (2008) Pattern of Dyslipidaemia among Nigerians with Type 2 DiabetesMellitus. Nigerian Journal of Clinical Practice, 11, 25-31.

[8] Piette JD, Kerr EA (2006). The Impact of Comorbid Chronic Conditions on Diabetes Care. Diabetes Care; 29: 725-731.

[9] Sowers JR. Recommendations for special populations: diabetes mellitus and the metabolic syndrome. Am J Hypertens. 2003; 16 (11 Pt 2):41S-5S.

[10] American Diabetes Association (ADA). Treatment of Hypertension in Adults With Diabetes. Diabetes Care, VOLUME 26, SUPPLEMENT 1, JANUARY 2003.

[11] Centers for Disease Control and Prevention. 2007 National diabetes fact sheet.

http://www.cdc.gov/diabetes/pubs/estimates07.htm\#8.

Accessed November 13, 2010.

[12] Colosia AD, Palencia R, Khan S (2013). Prevalence of hypertension and obesity in patients with type 2 diabetes mellitus in observational studies: A systematic literature review. Dovepress; 6: 327-338.

[13] Unadike B C, Eregie A, Ohwovoriole A E. Prevalence of hypertension amongst persons with diabetes mellitus in Benin City, Nigeria. Niger J Clin Pract [serial online] 2011[cited 2017 Aug 8]; 14:300-2. Available from: http://www.njcponline.com/text.asp?2011/14/3/300/86772

[14] Adogu, P O U, Chineke H N, Ewuzie M U, Enwere O O, Egenti N B. (2015) The Prevalence and Presentation Pattern of Diabetes Mellitus in Patients at Imo State University Teaching Hospital (IMSUTH) Orlu and Imo State Specialist Hospital (IMSSH) Umuguma Owerri (A 10-Year Retrospective Study: 1st November 2004 to 31st October 2013). Journal of Diabetes Mellitus, 5, 49-57. http://dx.doi.org/10.4236/jdm.2015.52006.

[15] Fillenbaum G, Pieper C, Cohen H, Cornoni-Huntley J, Guralnik J. Comorbidity of five chronic health conditions in elderly community residents: determinants and impact on mortality. J Gerontol A Biol Sci Med Sci 2000; 55: M84-89.

[16] UK Prospective Diabetes Study Group: Tight blood pressure control and risk of macrovascular and microvascular complications in type 2 diabetes BMJ 1998; 317:703-13.

[17] Nelson RG, Bennett PH, Beck GJ, Tan M, Knowler WC, Mitch WE, et al. Development and progression of renal disease in Pima Indians with noninsulin-dependent diabetes mellitus. N Engl J Med 1996; 335:1636-42.

[18] Amanda N. Long, DO and Samuel Dagogo-Jack, MD. The Comorbidities of Diabetes and Hypertension: Mechanisms and Approach to Target Organ Protection. J Clin Hypertens (Greenwich). 2011 April; 13(4): 244-251.

[19] American Diabetes Association (ADA). Standards of Medical Care in Diabetes- 2015.

http://care.diabetesjournals.org/content/suppl/2014/12/23/38.S upplement_1.DC1/January_Supplement_Combined_Final.699.pdf.

[20] Raymond Townsend, MD. April 2007 Issue of renal and urology news: Mechanism of Diabetic nephropathy. 2007; 1-4. 
[21] Carmine PK.: The renal vascular response to diabetes. Current Opinion in Nephrology and Hypertension. 2010 Jan; 19(1): 85-90:10.1097/MNH.0b013e32833240fc.

[22] UK Prospective Diabetes Study Group: Association of systolic blood pressure with macrovascular and microvascular complications of type 2 diabetes (UKPDS 36): prospective observational study. BMJ 2000; 321:412-9.

[23] Lorenzo E. Derchi, Giovanna Leoncini, Denise Parodi, Francesca Viazzi, Carlo Martinoli, Elena Ratto, Simone Vettoretti, Valentina Vaccaro, Valeria Falqui, Cinzia Tomolillo, Giacomo Deferrari, and Roberto Pontremoli. Mild Renal Dysfunction and Renal Vascular Resistance in Primary Hypertension. AJH 2005; 18:966-971.

[24] Naïke Bigé, Pierre Patrick Lévy, Patrice Callard, Jean-Manuel Faintuch, Valérie Chigot, Virginie Jousselin, Pierre Ronco, and Jean-Jacques Boffa. Renal arterial resistive index is associated with severe histological changes and poor renal outcome during chronic kidney disease. BMC Nephrology 2012, 13:139. http://www.biomedcentral.com/14712369/13/139.

[25] Richard J MacIsaac, Merlin C Thomas, Sianna Panagiotopoulos, Trudy J Smith, Huming Hao, D Geoffrey Matthews, George Jerums, Louise M Burrell and Piyush M Srivastava. Association between intrarenal arterial resistance and diastolic dysfunction in type 2 diabetes. Cardiovascular Diabetology 2008, 7:15 doi:10.1186/1475-2840-7-15.

[26] R. M. Bruno, A. Salvati, M. Barzacchi, K. Raimo, S. Taddei, L. Ghiadoni and A. Solini. Predictive value of dynamic renal resistive index (drin) for renal outcome in type 2 diabetes and essential hypertension: a prospective study. Cardiovascular Diabetology (2015) 14:63. DOI 10.1186/s12933-015-0227-y

[27] Ishimura E, Nishizawa Y, Kawagishi T, Okuno Y, Kogawa K, Fukumoto S, Maekawa K, Hosoi M, Inaba M, Emoto M, Morii H. Intrarenal hemodynamic abnormalities in diabetic nephropathy measured by duplex Doppler sonography. Kidney Int 1997;51:1920-1927.

[28] Cvitkoviæ Kuzmiæ A, Brkljaèiæ B, Ivankoviæ D, Galešiæ K. Doppler sonographic renal resistance index in healthy children. Eur Radiol 2000; 10:1644-1648.

[29] Francesca Viazzi, Giovanna Leoncini, Lorenzo E. Derchi, and Roberto Pontremoli Ultrasound Doppler renal resistive index: a useful tool for the management of the hypertensive patient. Journal of Hypertension 2014, 32:149-153.

[30] World Health Organization. Definition and diagnosis of diabetes mellitus and intermediate hyperglycaemia. http://www.who.int/diabetes/publications/Definition\%20and\% 20diagnosis $\% 20 \mathrm{of} \% 20$ diabetes_new.pdf

[31] Giles TD, Materson BJ, Cohn JN, Kostis JB. Definition and classification of hypertension: an update. J Clin Hypertens (Greenwich). 2009; 11: 611-4.

[32] Sherwani, S. I., Khan, H. A., Ekhzaimy, A., Masood, A., \& Sakharkar, M. K. (2016). Significance of HbA1c Test in Diagnosis and Prognosis of Diabetic Patients. Biomarker Insights, 11, 95-104. http://doi.org/10.4137/BMI.S38440

[33] Gillett MJ. International Expert Committee report on the role of the A1C assay in the diagnosis of diabetes. Diabetes Care. 2009; 32: 1327-34].
[34] Katzmarzyk, P. T., Hu, G., Cefalu, W. T., Mire, E., \& Bouchard, C. (2013). The Importance of Waist Circumference and BMI for Mortality Risk in Diabetic Adults. Diabetes Care, 36(10), 3128-3130. http://doi.org/10.2337/dc13-0219.

[35] American Diabetes Association Standards of medical care in diabetes-2013. Diabetes Care 2013;36 (Suppl. 1):S11-S66 [PMC free article] [PubMed]

[36] Kodama S, Horikawa C, Fujihara K, et al. Comparisons of the strength of associations with future type 2 diabetes risk among anthropometric obesity indicators, including waist-to-height io: a meta-analysis. Am J Epidemiol 2012; 176:959-969 [PubMed].

[37] Ishimura E, Nishizawa Y, Kawagishi T, Okuna Y, Kogawa K, Fukumoto $\mathrm{S}$, et al. Intrarenal hemodynamic abnormalities in diabetic nephropathy measured by duplex Doppler sonography. kidney Int. 1997;51:1920-1927.

[38] Dawha S, Ayoola OO, Ibitoye BO, Ikem RT, Arogundade FA. An assessment of factors influencing resistivity and pulsatility indices in diabetes mellitus Trop J Nephrol. 2014; 9: 15-22.

[39] Nejad MN, Jafari B, Alipour P. Arterial resistive index (RI) in type 2 Diabetic Nephropathy Stages and Healthy Controls. Iran J Radiol. 2009; 6(1):29-32.

[40] Thukral A, Mishra M, Srivastava V, kumar H, Dhar Dwivedi AN, Shukla RC et al. Determinants of intravascular resistance in Indian diabetic nephropathy patients: A Hospital based study. Int J vasc Med. 2011; 2011:656030.

[41] Bouissou H, Pieraggi MT, Julian M. Age related morphological changes of the arterial wall. In: Camilleri JP, Berry CL, Fiessinger JN, Barriety J, editors. Disease of the arterial wall. Berlin. Springer-Verlag 1989: 71-78).

[42] Nejad MN, Jafari B, Alipour P. Arterial resistive index (RI) in type 2 Diabetic Nephropathy Stages and Healthy Controls. Iran J Radiol. 2009; 6(1):29-32).

[43] Panaritis, A.V. Kyriakidis, M. Pyrgioti, L. Raffo, E. Anagnostopoulou, G. Gourniezaki, E. Koukou et al. Pulsatility Index of Temporal and Renal Arteries as an Early Finding of Arteriopathy in Diabetic Patients. Annals of Vascular Surgery, 19, (1): 80-83.

[44] Murray Epstein and James R. Sowers. Hypertension 1992; 19:403-418

[45] Elkayam U, Weber L, Campese VM, Massry SG, Rahimtoola SH. Renal hemodynamic effects of vasodilation with nifedipine and hydralazine in patients with heart failure. J Am Coll Cardiol. 1984 Dec; 4(6):1261-7.

[46] Licata, G., Scaglione, R., Ganguzza, A. et al. Eur J Clin Pharmacol (1993) 45: 307. https://doi.org/10.1007/BF00265946.

[47] Lorenzo E. Derchi, Giovanna Leoncini, Denise Parodi, Francesca Viazzi, Carlo Martinoli, Elena Ratto, Simone Vettoretti, Valentina Vaccaro, Valeria Falqui, Cinzia Tomolillo, Giacomo Deferrari, and Roberto Pontremoli. Mild Renal Dysfunction and Renal Vascular Resistance in Primary Hypertension. Am J Hypertens 2005; 18: 966-971. 